\title{
CORRESPONDENCE
}

\section{Survey data are still vital to science}

We have noticed a shift in the way funding agencies and journal editors are viewing observational science. It seems that the value of traditional surveys and exploration is being undermined particularly in the field of microbial ecology. But without these surveys, scientific advances will stall.

Apart from the Census of Marine Life (www.coml.org), it is becoming increasingly difficult to obtain funding for even small-scale surveys of life. This is despite the success of large-scale observational studies such as the Global Ocean Sampling metagenomic study (D. B. Rusch et al. PLoS Biol. 5, e77; 2007), which resulted in more than 100 papers that helped to generate and test hypotheses on marine microbial communities. Later, the TARA Oceans survey (http://oceans. taraexpeditions.org) used a similar experimental approach, incorporating statistical design and contextual metadata.

The resulting explosion of metagenomic discovery now extends to the human digestive tract (www.metahit.eu; http://nihroadmap.nih.gov/ hmp) and to the soil (www. terragenome.org; T. M. Vogel et al. Nature Rev. Microbiol. 7 , $252 ; 2009)$. Only now, and only with metagenomics, do we have the potential to crack open the microbial black box that operates all of Earth's ecosystems (see, for example, the Earth Microbiome Project: www.earthmicrobiome.org).

Charles Darwin's skills in using meticulous survey observations as a basis for scientific theory are still just as relevant today.

Jack Gilbert Argonne National Laboratory, USA. gilbertjack@gmail.com Ronald O'Dor Dalhousie
University, Canada.

Timothy Vogel University of Lyons, France.

\section{Innovation: lessons from UK policy}

I disagree with parts of Bhaven Sampat's assessment of the US Bayh-Dole Act on ownership of federally funded research (Nature 468, 755-756; 2010).

The act was passed as an agent of economic policy, not of social policy. It aimed to reconnect academic research to the national economic infrastructure by allowing universities to obtain patents on their research and then commercialize it. It bypassed 'top-down' rules established by the government.

Sampat implies that universities grant only exclusive licences. The Bayh-Dole Act aimed to liberate universities from the rigid government prescription that permitted only non-exclusive licensing of federally funded inventions (most start-up companies require an exclusive licence, for example). In practice, the licensing mix of academic institutions is much more nuanced $-61 \%$ of US licences in fiscal year 2009 were non-exclusive (Association of University Technology Managers survey).

The United Kingdom had its 'Bayh-Dole moment' in 1988, when Prime Minister Margaret Thatcher abolished the monopoly on British academic inventions held by the National Research and Development Corporation. But outside the largest UK universities, there was very little technology-licensing activity until 1999. Then the government introduced 'thirdstream' funding for knowledge transfer by universities. This essentially gave universities an economic development mandate and paid them to fulfil it.

Third-stream and university research funding were maintained in the UK government's budget in June 2010, despite most areas of government funding receiving $10-20 \%$ cuts. A $£ 200$-million (US\$312-million) programme was also established to create a network of proof-of-concept centres, based on the German Fraunhofer Center model (www.fraunhofer.de/en).

Lessons can be learned from the UK government's acknowledgement that academic research is the long-term driver of economic growth and that sufficient support and funding is necessary to deliver on its potential.

Ashley J. Stevens Boston University, USA.

astevens@bu.edu

\section{Evaluate impact of communication}

Effective communication between scientists and nonscientists calls for special evaluation and training procedures, not simply "more and better science" (Nature 468, 1032-1033; 2010).

The impact of science communications on target audiences needs evaluation. And effective evaluation requires upstream planning and clear objectives if it is to inform practice (E. Jensen \& B. Wagoner Cult. Psychol. 15, 217-228; 2009).

Unfortunately, institutions that sponsor science-communication activities are not always consistent in their evaluation requirements and rarely assess long-term impact. And when such projects are subject to independent evaluation, tenders are typically assessed either by the practitioners whose work is under scrutiny, or by staff without the relevant methodological expertise.

To enhance the quality of their engagement with the public and with policy-makers, scientists and other science communicators should make use of theories and results from the social sciences. Without training in media literacy, audience reception or the communication and sociology of science, communicators could find themselves rehearsing longdiscredited practices.

I propose that such training should be incorporated into scientists' graduate studies. This would spare governments and scientific institutions from reframing the funding and practice of science communication to protect the sciences and the public from the largely unacknowledged risks of miscommunication.

Eric Jensen University of Warwick, UK.

e.jensen@warwick.ac.uk

\section{Hungary works on toxic sludge soil}

Your revisit of last October's toxic sludge disaster in Hungary is reassuring in many respects (see go.nature.com/nhpboi). The Hungarian government is taking further steps to avert future ecological effects of the disaster.

The 800-hectare spill from an alumina factory was highly alkaline, leading to fears that arsenic and metals such as mercury and chromium could have leached into the soil and polluted the underlying water table after heavy rainfall.

Prompt governmental measures reduced the $\mathrm{pH}$ from 12 to $8-8.3$ and rescued the River Danube's Torna creek. The government is also removing the top 15-18 centimetres of soil at the accident site. It hopes to grow a bioremediating forest of Pteris vittata, a fern that hyperaccumulates arsenic, to help restore soil conditions and revive the former flora and fauna. Poonam Kaushik Bakhshi University College London, UK. poonamkaushik@gmail.com 